\title{
181. Continuity of Stochastic Processes on Metric Spaces
}

\author{
By Takayuki KAWADA \\ Kobe College of Commerce
}

(Comm. by Kinjirô KUnUGI, M. J. A., Sept. 12, 1970)

1. After A. N. Kolmogorov had presented the continuity condition of stochastic processes ([5]), several generalizations have been considered (e.g. [1]-[4]). But H. Cramér's idea in [1] permits us to obtain the continuity conditions in the more general situations; Let $\{x(t, \omega) ; t \in S\}$ be stochastic processes, based on a probability space $(\Omega, \mathscr{B}, P)$, of which parameter $t$ runs over a compact metric space $(S, d)$, and of which value is taken in a complete metric space $(M, r)$. Here their metrics are $d$ and $r$, respectively. Denote by $N(\varepsilon)$ the minimal number of $\varepsilon$-net of the space $S .{ }^{*}$ Then we establish the followings:

Theorem 1. Suppose that

$$
P[r(x(t), x(s)) \geq g(d(t, s))] \leq q(d(t, s)),
$$

where $g(h)$ and $q(h)$ are even, non-decreasing functions in $h>0$, and that

$$
\sum_{n=1}^{\infty} g\left(2^{-n}\right)<\infty, \quad \sum_{n=1}^{\infty} N^{2}\left(2^{-n-1}\right) \cdot q\left(2^{-n+2}\right)<\infty .
$$

Then the stochastic processes have continuous version.

Theorem 2. Suppose (1) above and that

$$
\sum_{k=1}^{\infty} g\left(2^{-n-k}\right)<C \cdot g\left(2^{-n}\right), \quad \sum_{n=1}^{\infty} N^{2}\left(2^{-n-1}\right) \cdot q\left(2^{-n+2}\right)<\infty,
$$

and

$$
g(4 h)<C^{\prime} \cdot g(h) \quad \text { for sufficiently small } h,
$$

where $n$ is any positive integer, and $C$ and $C^{\prime}$ are some positive constants. Then the stochastic processes have g-Hölder continuous version.

2. By $A_{n}$, we denote the elements of $2^{-n}$-net; $A_{n}=\left\{t_{n}^{k} ; k=1,2\right.$, $\left.\cdots, N\left(2^{-n}\right)\right\}, n=1,2,3, \cdots$, and we set $D=\bigcup_{n=1}^{\infty} A_{n}$. By $F$, we define the space of all $M$-valued, non-random functions, and by $F_{n}$ the elements of $F$ such that

$$
\begin{aligned}
& F_{n}=\{f(t) ; r(f(x), f(y)) \leqq g(d(x, y)), \\
& \left.\quad \text { for } \quad(x, y), x \in A_{n}, y \in A_{n+1} \text { and } d(x, y) \leqq 2^{-n+2}\right\}
\end{aligned}
$$

where $g(h)$ is one cited in (1). Further, we set $U_{n}=\bigcap_{j=n}^{\infty} F_{j}$, and

\footnotetext{
*) $\log N(\varepsilon)$ is called $\varepsilon$-entropy of the space $S$.
} 
$U=\bigcup_{n=1}^{\infty} U_{n}$. The function $f_{D}(t)$ is denoted as the restriction of $f(t) \in F$ to $D$, and $f_{D}(t+)$ means the limiting value of $\left\{f_{D}\left(t_{n}\right), t_{n} \in A_{n}, d\left(t, t_{n}\right)\right.$ $\left.\leq 2^{-n+1}, n=1,2, \cdots\right\}$, if it exists. Then we have;

Lemma 1. If $f(t) \in U, f_{D}(t+)$ exists uniquely and independently of the sequence $\left\{t_{n}\right\}$.

Proof. For any positive $\varepsilon>0$, there exists a number $n_{0}$ such that $\sum_{k=n_{0}}^{\infty} g\left(2^{-k}\right)<\varepsilon$. For a sequence $\left\{t_{n} \in A_{n}, d\left(t, t_{n}\right) \leq 2^{-n+1}, n=1,2,3, \cdots\right\}$, and for any $p>q>1+\max \left(N, n_{0}\right)$ where $N$ is the smallest number satisfying $f(t) \in U_{N}{ }^{* *}$, we estimate

$$
\begin{aligned}
r\left(f_{D}\left(t_{q}\right), f_{D}\left(t_{p}\right)\right) & \leqq \sum_{l=q}^{p-1} r\left(f_{D}\left(t_{l}\right), f_{D}\left(t_{l+1}\right)\right) \leqq \sum_{l=q}^{p-1} g\left(d\left(t_{l}, t_{l+1}\right)\right) \\
& \leqq \sum_{l=q}^{\infty} g\left(2^{-l+2}\right) \leqq \sum_{l=n_{0}}^{\infty} g\left(2^{-l}\right)<\varepsilon,
\end{aligned}
$$

since $d\left(t_{l}, t_{l+1}\right) \leq d\left(t_{l}, t\right)+d\left(t, t_{l+1}\right) \leq 2^{-l+1}+2^{-l} \leq 2^{-l+2}$, and $t_{l} \in A_{l}, t_{l+1}$ $\in A_{l+1}$. Thus, we have

$$
\lim _{l \rightarrow \infty} r\left(f_{D}\left(t_{l}\right), f_{0}\right)=0
$$

This $f_{0}$ does not depend on the sequence ; In fact, if we have a different value $f_{0}^{\prime}$ for another sequence $\left\{t_{n}^{\prime} ; t_{n}^{\prime} \in A_{n}, d\left(t, t_{n}^{\prime}\right) \leq 2^{-n+1}, n=1,2,3, \cdots\right\}$, we can observe that, since $d\left(t_{n}, t_{n+1}^{\prime}\right) \leq d\left(t_{n}, t\right)+d\left(t, t_{n+1}^{\prime}\right) \leq 2^{-n+1}+2^{-n}$ $\leq 2^{-n+2}$,

$$
\begin{aligned}
r\left(f_{0}, f_{0}^{\prime}\right) & \leq r\left(f_{0}, f_{D}\left(t_{n}\right)\right)+r\left(f_{D}\left(t_{n}\right), f_{D}\left(t_{n+1}^{\prime}\right)\right)+r\left(f_{D}\left(t_{n+1}^{\prime}\right), f_{0}^{\prime}\right) \\
& \leq 2 \varepsilon+g\left(2^{-n+2}\right),
\end{aligned}
$$

for any $\varepsilon>0$ and for sufficiently large $n$. This proves the Lemma.

Lemma 2. For $f(t) \in U$, we set $h(t)=f_{D}(t+)$. Then $h(t)$ is continuous in $t$.

Proof. We shall show by contradiction; Assume that there exists a sequence $\left\{x_{n} ; x_{n} \in S\right\}$ converging to $t$ such that $\lim _{n \rightarrow \infty} r\left(h\left(x_{n}\right), h(t)\right) \neq 0$. For each integer $m$, we can find a point $x_{n_{m}}$ in the sequence $\left\{x_{n}\right\}$ satisfying $d\left(t, x_{n_{m}}\right) \leq 2^{-m}$, and further for each $x_{n_{m}}$, there exists a sequence $\left\{y_{q}\left(n_{m}\right) ; y_{q}\left(n_{m}\right) \in A_{q}, d\left(x_{n_{m}}, y_{q}\left(n_{m}\right)\right) \leq 2^{-q}, q=1,2, \cdots\right\}$, for which we have $\lim r\left(f_{D}\left(y_{q}\left(n_{m}\right), h\left(x_{n_{m}}\right)\right)=0\right.$, due to Lemma 1. Since

$$
d\left(t, y_{m}\left(n_{m}\right)\right) \leq d\left(t, x_{n_{m}}\right)+d\left(x_{n_{m}}, y_{m}\left(n_{m}\right)\right) \leq 2^{-m}+2^{-m}=2^{-m+1},
$$

and $y_{m}\left(n_{m}\right) \in A_{m}$, we have $\lim r\left(f_{D}\left(y_{m}\left(n_{m}\right)\right), h(t)\right)=0$. Further we estimate

$$
\begin{aligned}
r\left(h(t), h\left(x_{n_{m}}\right)\right) \leqq & r\left(h(t), f_{D}\left(y_{m}\left(n_{m}\right)\right)\right)+r\left(f_{D}\left(y_{m}\left(n_{m}\right)\right), h\left(x_{n_{m}}\right)\right) \\
\leqq & r\left(h(t), f_{D}\left(y_{m}\left(n_{m}\right)\right)\right)+\sum_{q=m}^{Q-1} r\left(f_{D}\left(y_{p}\left(n_{m}\right)\right), f_{D}\left(y_{q+1}\left(n_{m}\right)\right)\right) \\
& +r\left(f_{D}\left(y_{Q}\left(n_{m}\right)\right), h\left(x_{n_{m}}\right)\right) .
\end{aligned}
$$

Here, by making the integer $Q$ so large, we have for any $\varepsilon>0$,

**) We shall not repeat below the indication of the number to which class of $U$ a function $f(t)$ belongs, when it is clear in the context. 


$$
\begin{gathered}
\sum_{q=m}^{Q-1} r\left(f_{D}\left(y_{q}\left(n_{m}\right)\right), f_{D}\left(y_{q+1}\left(n_{m}\right)\right)\right)+r\left(f_{D}\left(y_{Q}\left(n_{m}\right)\right), h\left(x_{n_{m}}\right)\right) \\
\leqq \sum_{q=m}^{\infty} r\left(f_{D}\left(y_{q}\left(n_{m}\right)\right), f_{D}\left(y_{q+1}\left(n_{m}\right)\right)\right)+\varepsilon .
\end{gathered}
$$

Further, since $d\left(y_{q}\left(n_{m}\right), y_{q+1}\left(n_{m}\right)\right) \leq d\left(y_{q}\left(n_{m}\right), x_{n_{m}}\right)+d\left(x_{n_{m}}, y_{q+1}\left(n_{m}\right)\right) \leq 2^{-q}$ $+2^{-q-1} \leqq 2^{-q+2}$, it holds

As a result, we have

$$
\sum_{q=m}^{\infty} r\left(f_{D}\left(y_{q}\left(n_{m}\right)\right), f_{D}\left(y_{q+1}\left(n_{m}\right)\right)\right) \leqq \sum_{q=m}^{\infty} g\left(2^{-q+2}\right) .
$$

$$
r\left(h(t), h\left(x_{n_{m}}\right)\right) \leqq r\left(h(t), f_{D}\left(y_{m}\left(n_{m}\right)\right)\right)+\sum_{k=m-2}^{\infty} g\left(2^{-k}\right),
$$

which implies, for sufficiently large $m$, a contradiction to the hypothesis above.

Lemma 3. Let $\{x(t, \omega) ; t \in S\}$ be stochastic processes satisfying the conditions (1) and (2). Then

$$
P[x(t, \omega) \in U]=1 .
$$

Proof. For the complement of $F_{n}, F_{n}^{c}$ we have

$$
\begin{aligned}
P\left[x(t, \omega) \in F_{n}^{c}\right] & \leqq P\left[\max _{\substack{(t, s) \in A_{n} \times A_{n}+1 \\
d(t, s) \cong 2-n+2}} r(x(t), x(s))>g(d(t, s))\right] \\
& \leqq \sum_{\substack{(t, s) \in A n \times A_{n+1} \\
d(t, s) \Sigma^{2}-n+2}} P[r(x(t), x(s)>g(d(t, s))] \\
& \leqq N\left(2^{-n}\right) \cdot N\left(2^{-n-1}\right) \cdot q\left(2^{-n+2}\right) .
\end{aligned}
$$

Since we have $U_{n}^{c}=\bigcup_{j=n}^{\infty} F_{j}^{c}$, and

$$
\begin{array}{r}
P\left[x(t, \omega) \in U_{n}^{c}\right] \leqq \sum_{j=n}^{\infty} P\left[x(t, \omega) \in F_{j}^{c}\right] \\
\leqq \sum_{j=n}^{\infty} N^{2}\left(2^{-n-1}\right) \cdot q\left(2^{-n+2}\right),
\end{array}
$$

we obtain

$$
\begin{gathered}
P\left[x(t, \omega) \in U^{c}\right]=\lim _{n \rightarrow \infty} P\left[x(t, \omega) \in U_{n}^{c}\right]=0, \\
P[x(t, \omega) \in U]=0 .
\end{gathered}
$$

3. Proof of Theorem 1. For each $t$ in $S$, we define $\omega$-sets, $V_{t}$ and $W_{t}$ respectively as follows ;

We shall prove that

$$
\begin{aligned}
V_{t} & =\left\{\omega ; x(t, \omega)=x_{D}(t+, \omega)\right\}, \\
W_{t} & =\left\{\omega ; x(t, \omega) \neq x_{D}(t+, \omega)\right\} .
\end{aligned}
$$

$$
P\left[V_{t}\right]=1 \text {, and } P\left[W_{t}\right]=0 .
$$

For $t \in S$, we choose a sequence $\left\{t_{k} ; t_{k} \in A_{k}, d\left(t, t_{k}\right) \leq 2^{-k+1}, d\left(t, t_{k+1}\right)\right.$ $\left.\leq d\left(t, t_{k}\right) ; k=1,2, \cdots\right\}$. Then, due to Lemmas 1 and 3 , we have

$$
P\left[r\left(x(t), x\left(t_{k}\right)\right) \geqq g\left(d\left(t, t_{k}\right)\right)\right] \leq q\left(d\left(t, t_{k}\right)\right),
$$

and

$$
\lim _{k \rightarrow \infty} r\left(x\left(t_{k}, \omega\right), x_{D}(t+, \omega)\right)=0,
$$

with probability one; i.e. for any $\varepsilon>0$ and any $\delta>0$, and for some integer $K$ it holds for every $k>K$ 


$$
P\left[r\left(x\left(t_{k}\right), x_{D}(t+)\right)>\delta / 2\right] \leq \varepsilon .
$$

We set, for this $\delta, m_{\delta}=\min \left\{l ; g\left(d\left(t, t_{l}\right)\right)<\delta / 2\right\}$. Then we estimate for every $j>\max \left(m_{\tilde{\delta}}, K\right)$,

Hence

$$
P\left[r\left(x(t), x\left(t_{j}\right)\right)>\delta / 2\right] \leqq q\left(d\left(t, t_{j}\right)\right) .
$$

Thus we get

$$
\begin{aligned}
& P\left[r\left(x(t), x_{D}(t+)\right)>\delta\right] \\
\leq & P\left[r\left(x(t), x\left(t_{j}\right)\right)>\delta / 2\right]+P\left[r\left(x\left(t_{j}\right), x_{D}(t+)\right)>\delta / 2\right] \\
\leq & q\left(d\left(t, t_{j}\right)\right)+\varepsilon .
\end{aligned}
$$

$$
\begin{gathered}
P\left[r\left(x(t), x_{D}(t+)\right)>\delta\right]=0, \\
P\left[V_{t}\right]=1 .
\end{gathered}
$$

Clearly, $V_{t} \cap W_{t}=\emptyset$, and therefore $P\left[W_{t}\right]=0$. For every $t$ in $S$ and $\omega$, we define

$$
y(t, \omega)= \begin{cases}x_{D}(t+, \omega) ; & \omega \in V_{t}, \\ \alpha \in M ; & \omega \in W_{t} .\end{cases}
$$

It is observed that the stochastic processes $\{y(t, \omega)\}$ is equivalent to the $\{x(t, \omega)\}$ and $y(t, \omega)$ is continuous in $t$ with probability one. The proof of Theorem 1 is completed.

4. Proof of Theorem 2. At first we remark that the condition (3) implies (2). In fact, it is obvious due to the following;

$$
\sum_{k=1}^{\infty} g\left(2^{-k}\right)=\sum_{k=1}^{n} g\left(2^{-k}\right)+\sum_{k=n+1}^{\infty} g\left(2^{-k}\right) \leqq \sum_{k=1}^{n} g\left(2^{-k}\right)+C \cdot g\left(2^{-n}\right) .
$$

This implies the sample-continuity. Next we estimate

$$
\begin{aligned}
& P\left[\max _{\substack{t_{n} \in A_{n}, t_{n+1} \in A_{n}+1 \\
d\left(t_{n}, t_{n+1}\right) \leq 2-n+2}} r\left(x\left(t_{n}\right), x\left(t_{n+1}\right)\right)>g\left(d\left(t_{n}, t_{n+1}\right)\right)\right] \\
\leqq & \sum_{\substack{t_{n} \in A_{n}, t_{n+1} \in A_{n+1} \\
d\left(t_{n}, t_{n+1}\right) \leq 2}} P\left[r\left(x\left(t_{n}\right), x\left(t_{n+1}\right)\right)>g\left(d\left(t_{n}, t_{n+1}\right)\right)\right] \\
\leqq & N^{2}\left(2^{-n-1}\right) \cdot q\left(2^{-n+2}\right) .
\end{aligned}
$$

By (3) and Borel-Cantelli lemma, there exists a number $\nu(\omega)$ with probability one such that, for any $n>\nu(\omega)$ and for any pair $\left(t_{n}, t_{n+1}\right)$, $d\left(t_{n}, t_{n+1}\right) \leq 2^{-n+2}$, it holds

$$
r\left(x\left(t_{n}\right), x\left(t_{n+1}\right)\right) \leq g\left(d\left(t_{n}, t_{n+1}\right)\right) \leq g\left(2^{-n+2}\right) .
$$

We shall prove that for a $t_{m} \in A_{m}$ satisfying $d\left(t_{m}, t_{n}\right) \leq 2^{-n+2}, t_{n} \in A_{n}$, and $m>n>\nu(\omega)$, it holds

$$
r\left(x\left(t_{m}\right), x\left(t_{n}\right)\right) \leq C^{\prime \prime} \cdot g\left(2^{-n+1}\right),
$$

where $C^{\prime \prime}$ is some positive constant. For such $t_{m}$, we can find a sequence $\left\{t_{l} ; t_{l} \in A_{l}, d\left(t_{m}, t_{l}\right) \leq 2^{-l} ; l=n, n+1, n+2, \cdots, m\right\}$. Therefore we get the following estimate; Since $d\left(t_{l}, t_{l+1}\right) \leq 2^{-l+1}$,

$$
\begin{aligned}
r\left(x\left(t_{m}\right), x\left(t_{n}\right)\right) & \leqq \sum_{k=0}^{m-n-1} r\left(x\left(t_{n+k+1}\right), x\left(t_{n+k}\right)\right) \leqq \sum_{k=0}^{\infty} g\left(2^{-n-k+1}\right) \\
& \leqq g\left(2^{-n+1}\right)+g\left(2^{-n}\right)+C \cdot g\left(2^{-n}\right) \leqq C^{\prime \prime} \cdot g\left(2^{-n+1}\right) .
\end{aligned}
$$

Thus (5) is verified. Further (5) holds for any $t$ in $S$ satisfying $d\left(t, t_{n}\right)$ $\leqq 2^{-n+1}, t_{n} \in A_{n}$. In fact, taking a sequence $\left\{t_{p} ; t_{p} \in A_{p}, d\left(t, t_{p}\right) \leq 2^{-p}\right.$; 
$p=1,2, \cdots\}$, we see that, for any $\varepsilon>0, r\left(x\left(t_{p}\right), x(t)\right)<\varepsilon$ for sufficiently large $p$, and that, since for $p>n>\nu(\omega), d\left(t_{p}, t_{n}\right) \leq d\left(t_{p}, t\right)+d\left(t, t_{n}\right) \leq 2^{-p}$ $+2^{-n+1} \leq 2^{-n+2}$, it holds for sufficiently large $p$

$$
\begin{aligned}
r\left(x(t), x\left(t_{n}\right)\right) & \leqq r\left(x(t), x\left(t_{p}\right)\right)+r\left(x\left(t_{p}\right), x\left(t_{n}\right)\right) \\
& \leqq \varepsilon+C^{\prime \prime} \cdot g\left(2^{-n+1}\right) .
\end{aligned}
$$

This implies that (5) holds even for $t \in S$ satisfying $d\left(t, t_{n}\right) \leq 2^{-n+1}$, and $n>\nu(\omega)$. Using this fact, we shall show $g$-Hölder continuity. Set a number $\delta(\omega)=2^{-\nu(\omega)}$. For any pair of points $(t, s)$ such that $d(t, s)<\delta(\omega)$, there exists an integer $n$ satisfying

$$
n>\nu(\omega) \text {, and } 2^{-n-1} \leq d(t, s)<2^{-n} \text {. }
$$

On the other hand, we can find a $t_{n} \in A_{n}$ satisfying $d\left(t, t_{n}\right) \leq 2^{-n}$. Since $d\left(t_{n}, s\right) \leq d\left(t_{n}, t\right)+d(t, s) \leq 2^{-n}+2^{-n}=2^{-n+1}$, we have

$$
\begin{aligned}
r(x(t), x(s)) & \leq r\left(x(t), x\left(t_{n}\right)\right)+r\left(x\left(t_{n}\right), x(s)\right) \\
& \leq C^{\prime \prime} \cdot g\left(2^{-n+1}\right)+C^{\prime \prime} g\left(2^{-n+1}\right) \\
& \leq 2 C^{\prime \prime} g\left(4 \cdot 2^{-n-1}\right) \\
& \leq 2 C^{\prime \prime} g(4 d(t, s)) .
\end{aligned}
$$

Thus we obtain with probability one, for $d(t, s)<\delta(\omega)$, due to (4)

$$
r(x(t), x(s)) \leqq C^{\prime} g(d(t, s))
$$

where $C^{\prime}=2 C^{\prime \prime}$. This proves Theorem 2 .

\section{References}

[1] Cramér, H., and M. R. Leadbetter: Stationary and Related Stochastic Processes. Wiley, New York (1967).

[2] Jadrenko, J. M.: Local properties of sample functions of random fields. Visnik Kiev Univ. Ser. Math. Meh., 103-112 (1967) (in Ukrainian), MR (1969) \#1732.

[ 3 ] Leadbetter, M. R., and E. W. Weissner: On continuity and other analytic properties of Stochastic process sample functions. Proc. Amer. Math. Soc., 22, 291-294 (1969), MR (1970) \#4921.

[4] Loève, M.: Probability Theory (2nd-edit.). Van Nostrand, New York (1963).

[5] Slutsky, E.: Alcune prosizioni sulla teoria della funzioni aleatorie. Giorn. Ist. Ital. Attuari, 8, 193-199 (1937). 